\title{
Ion-Dipole Complex Formation from Deprotonated Phenol Fatty Acid Esters Evidenced By Using Gas-Phase Labeling Combined with Tandem Mass Spectrometry
}

\author{
F. Fournier, B. Remaud, T. Blasco, and J. C. Tabet \\ Laboratoire de Chimie Organique Structuralc, URA 455, Université Pierre et Marie Curie, Paris, France
}

\begin{abstract}
The behavior of para-hydroxy-benzyl and hydroxy-phenylethyl fatty acid esters and methoxy derivatives toward the $\mathrm{NH}_{3} / \mathrm{NH}_{2}^{-}$system was investigated. Under these negative ion chemical ionization (NICI) conditions, proton abstraction takes place mainly at the more acidic site (i.e., phenol); however, this reaction is not entirely regioselective. Using NICI-ND conditions, both isomeric phenoxide and enolate molecular species are produced in competition from these phenol esters. Their respective low-energy collision-activated dissociation spectra are studied, and they strongly differ, showing that these molecular species are not convertible to a common structure. Analysis of specific fragmentations of the OD-enolate parent species labeled by $\mathrm{ND}_{3}$ in the gas phase, indicates that by charge-promoted cleavage, isomerization into an ion-dipole intermediate takes place prior to dissociation. This complex, containing a ketene moiety, isomerizes into different isomeric forms via two consecutive proton transfers: the first, which is very exothermic, is irteversible in contrast to the second, less exothermic reaction, which occurs via a reversible process. It is evidenced by the loss of labeling at phenol or enolizable sites in the fragment ions. Such a stepwise process does not take place from the phenoxide parent ion, which preferentially yields a very stable carboxylate ion. A thermochemical approach, using estimated acidity values, yields a rationalization of the observed reactivities of the various substrates studied. ( $($ Am Soc Mass Spectrom 1993, 4, 343-351)
\end{abstract}

$\mathrm{O}$ ver the past few years, different tandem mass spectrometry investigations of the ion structures of decomposing molecular species showed evidence of molecular isomerization into ion-dipole complexes [1]. It has been shown that such isomerization processes take place prior to metastable decomposition [or collision-activated dissociation (CAD) processes] of molecular ion species prepared by electron impact, chemical ionization (in positive or negative ion mode), and fast-atom bombardment (FAB). Furthermore, these studies have shown that formation of ion-dipole complexes [1] as intermediates generally implies a charge-promoted cleavage process that can be accompanied, for instance, by radical or proton transfer (reversible or not), according to thermochemical considerations.

Insofar as negative ion species are concerned, such stepwise decomposition pathways have been described in the case of monofunctional compounds (e.g.,

Address reprint requests to Jean-Claude Tabet, Laboratoire de Chimie Organique Structurale, Universite Pierre et Marie Curie, 8 Rue Cuvier, 75230 Paris Cedex 05, France. alcohols, ketones, ethers, and esters) [2] ionized under negative ion chemical ionization (NICI) conditions. It has been shown that such isomerization is considered to be a rate-determining step [3]. From unsymmetrical ketones, two isomeric enolate structures are produced in competition, which leads to a more complicated situation concerning the interpretation of isomerization mechanisms; however, such enolate structures are not convertible [4]. Therefore, the isomeric enolates produced trom labeled, unsymmetrical ketones were distinguished because under collision they decomposed via different stepwise pathways [5].

A similar situation characterizes compounds containing two (or more) different types of acidic groups because gas-phase deprotonation can competitively occur at different sites. Thus, the $[\mathrm{M}-\mathrm{H}]^{-}$ions produced can be two (or more) isomeric ion structures; however, these structures can be convertible via exothermic proton transfer if there are neighboring acidic sites as occurs with natural compounds (e.g., glycosidic compounds [6, 7], amino acids [8], and peptides [9]). When the proton transfer from acidic site to negative charge is sterically hindered, then isomeric 
$[\mathrm{M}-\mathrm{H}]^{-}$species are unconvertible, as observed from unsymmetrical ketones. The relative contribution of these discrete structures in the $[\mathrm{M}-\mathrm{H}]^{-}$ion depends entirely on the relative acidities of both functional groups toward the gas-phase reagent.

On the other hand, the ion distribution is very much influenced by the $[\mathrm{M}-\mathrm{H}]^{-}$ion preparation mode when acidities of functional groups sufficiently differ, as demonstrated in a previous study [10] of $17 \beta$-estradiol-17-fatty esters using $\mathrm{FAB}$ and NICI combined with tandem mass spectrometry. Indeed, $\mathrm{CAD}$ spectra of the corresponding $[\mathrm{M}-\mathrm{H}]^{-}$species present different fingerprints according to the ion mode preparation. For instance, it has been shown that $[\mathrm{M}-\mathrm{H}]^{-}$ ions prepared under $\mathrm{FAB}$ conditions had a phenoxide structure exclusively [11], which was not the case in NICI ammonia, where both phenoxide and enolate species were produced in competition. Decomposition of these phenoxide species, under low-collision energy conditions, implied an ester bond cleavage via stepwise pathways, according to mechanisms previously reported in the literature [12, 13]; however, from investigation of the $17 \beta$-estradiol-17-fatty ester decompositions, it appeared that two possible ester cleavages could be induced, either by negative charge or not (quasi-thermal process), leading to a confusing mechanistic interpretation [11].

The objective of the study described here is to find a substrate of medium size, such as the following phenol fatty acid esters (e.g., palmitate) in which (1) the two acidic sites are not neighboring, and (2) both dissociation processes are induced by the negative charge. Such a model allows unambiguous investigation of stepwise decomposition of $\left[\mathrm{M}-\mathrm{H}^{-}\right.$ions occurring via isomerization into ion-dipole complexes according to the negative charge location at different acidic sites. These implied fragmentations are analogous to those of aliphatic monofunctional esters [2]:

$$
\begin{gathered}
(p) \mathrm{RO}-\mathrm{C}_{6} \mathrm{H}_{4}-\left(\mathrm{CH}_{2}\right)_{n}-\mathrm{O}-\mathrm{CO}-\mathrm{CR}_{2}^{\prime}-\left(\mathrm{CH}_{2}\right)_{13}-\mathrm{CH}_{3} \\
n=1: \quad \mathrm{R}=\mathrm{R}^{\prime}=\mathrm{H}\left(1, \mathrm{MW} \mathrm{362)} ; \mathrm{R}=\mathrm{D}, \mathrm{R}^{\prime}=\mathrm{H}\left(1_{\mathrm{d}}, \mathrm{MW} \mathrm{363);} \quad \text { and } \mathrm{R}=\mathrm{CH}_{3}, \mathrm{R}^{\prime}=\mathrm{H}(2, \mathrm{MW} \mathrm{376})\right.\right. \\
n=2: \quad \mathrm{R}=\mathrm{H}, \mathrm{R}^{\prime}=\mathrm{H}\left(3, \mathrm{MW} \mathrm{376)} ; \quad \mathrm{R}=\mathrm{D}, \mathrm{R}^{\prime}=\mathrm{H}\left(3_{\mathrm{d}}, \mathrm{MW} \mathrm{377)} ; \quad \text { and } \mathrm{R}=\mathrm{H}, \mathrm{R}^{\prime}=\mathrm{D}\left(\mathbf{3}_{\mathrm{d} 2}, \mathrm{MW} 378\right)\right.\right.
\end{gathered}
$$

These characteristic decompositions seem to take place via stepwise pathways requiring exothermic proton transfer isomerizations. To rationalize the observed orientation of proton transfer prior to dissociation reactions, gas-phase acidities provided from the literature could prove to be useful after several approximations that consider that a long-chain presence can increase acidity owing to a charge stabilization by a better solvation via coiling of conformation (i.e., increase in polarizability). This approach will allow an unambiguous mechanistic study with larger molecules (i.e., substituted by a long-chain ester) than those currently studied for this purpose.

\section{Results and Discussion}

NICI-NH ${ }_{3}$ mass spectra of the phenol esters present intense $[\mathrm{M}-\mathrm{H}]^{-}$peaks at $\mathrm{m} / z \quad 361$ and $\mathrm{m} / z 375$ from 1 and 3 , respectively, and an intense signal at $m / z 255$ corresponding to the carboxylate $\mathrm{R}-\mathrm{COO}^{-}$ fragment ion. Because $[\mathrm{M}-\mathrm{H}]^{-}$ions are produced as the major ions from these different esters, it is possible to investigate their respective dissociations under low-collision energy conditions, as shown in Table 1.

In particular, the CAD spectra display two series of complementary fragment ions at $m / z$ 105-255 and $m / z$ 123-237 from $\left[1-\mathrm{H}^{-}\right.$and at $m / z \quad 119-255$ and $m / z 137-m / z 237$ from $\left[3-\mathrm{H}^{-}\right.$, whereas only one pair of complementary ions at $\mathrm{m} / z 137$ and $m / z 237$ is observed from $[2-\mathrm{H}]^{-}$decompositions. Formally, from the phenol esters 1 and 3 , the common fragment ions at $m / z 255$ and 237 correspond to fatty ester fragments, the carboxylate $\mathrm{CH}_{3}\left(\mathrm{CH}_{2}\right)_{14}-\mathrm{COO}^{-}$and ynolate $\mathrm{CH}_{3}\left(\mathrm{CH}_{2}\right)_{13}-\mathrm{C}=\mathrm{C}-\mathrm{O}^{-}$ions, respectively [10-13]. Complementary ions are observed at $\mathrm{m} / \mathrm{z} 105$ and 123 for $\mathbf{1}$, whose formal structures are the $\mathrm{O}=\mathrm{C}_{6} \mathrm{H}_{4}=\mathrm{CH}^{-}$en-ylide and the $\mathrm{HO}-\mathrm{CH}_{2}-\mathrm{C}_{6}$ $\mathrm{H}_{4}-\mathrm{O}^{-}$phenoxide (or, eventually, the alkoxide $\mathrm{HO}-\mathrm{C}_{6} \mathrm{H}_{4}-\mathrm{CH}_{2}-\mathrm{O}^{-}$form), respectively. From 3 the corresponding phenoxide fragment ions are $-\mathrm{O}-\mathrm{C}_{6} \mathrm{H}_{4}-\mathrm{CH}=\mathrm{CH}_{2}, m / z 119$ (or isomeric forms) and ${ }^{-} \mathrm{O}-\mathrm{C}_{6} \mathrm{H}_{4}-\mathrm{CH}_{2} \mathrm{CH}_{2} \mathrm{OH}, \mathrm{m} / z 137$ (or the less stable isomeric $\mathrm{HO}-\mathrm{C}_{6} \mathrm{H}_{4}-\mathrm{CH}_{2} \mathrm{CH}_{2} \mathrm{O}^{-}$alkoxide).

It can also be noted that in the $\mathrm{CAD}$ spectrum of $[1-\mathrm{H}]^{-}, m / z 361$, a significant signal appears at $m / z$ 317 , corresponding to elimination of $\mathrm{CO}_{2}$. This elimination does not take place from the methoxy derivative $\left[2-\mathrm{H}^{-}\right.$ion nor from the phenol ester $\left[3-\mathrm{H}^{-}\right.$ ion, which, instead, preferentially loses $\mathrm{CH}_{2} \mathrm{O}$ (ion at $m / z$ 345). Alternatively, the fragment ion at $m / z \quad 107$ seems to be formally produced either by benzylic cleavage (i.e., loss of $\mathrm{CH}_{2} \mathrm{O}$ ) from the alkoxide ${ }^{-} \mathrm{O}-\left(\mathrm{CH}_{2}\right)_{2}-\mathrm{C}_{6} \mathrm{H}_{4}-\mathrm{OH}(\mathrm{m} / z$ 137) ion or directly from the deprotonated $[3-\mathrm{H}]^{-}$molecules (seen later).

The different behavior toward collisions between the deprotonated phenol esters (i.e., $[1-\mathrm{H}]^{-}$and $[3-\mathrm{H}]^{-}$) and the deprotonated methoxy derivative $[2-\mathrm{H}]^{-}$suggests that the decomposition orientation is strongly influenced by charge location:

1. The formation of the carboxylate $m / z 255$ ions from $[1-\mathrm{H}]^{-}$and $[3-\mathrm{H}]^{-}$should be enhanced from deprotonated species within a phenoxide struc- 
Table 1. Low-energy CAD spectra ( $E_{1 \mathrm{ab}}=10 \mathrm{eV}$, single-collision conditions) of the deprotonated $[1-\mathrm{H}]^{-}(m / z 361)$ and $[3-\mathrm{H}]^{-}(m / z 375)$ phenol ester ions and deprotonated methoxy $\left[2-\mathrm{H}^{-}\right.$ester ions.

\begin{tabular}{crrrrrr}
\hline Compound $\left(m / z[\mathrm{M}-\mathrm{H}]^{-}\right)$ & \multicolumn{5}{c}{ Daughter ion (abundances) } \\
\hline \hline $1(m / z 361)$ & $95(2.0)$ & $105(4.5)$ & $123(62)$ & $237(25)$ & $255(100)$ & $317(55)$ \\
$2(m / z 375)$ & $107(2.9)$ & $121(1.1)$ & $137(19)$ & $237(100)$ & $255(-)$ & \\
$3(m / z 375)$ & $107(4.1)$ & $119(5.3)$ & $137(74)$ & $237(33)$ & $255(100)$ & $345(26)$
\end{tabular}

"Abundances are relative to the most abundant fragment ion.

ture such as ${ }^{-} \mathrm{O}-\mathrm{C}_{6} \mathrm{H}_{4}-\left(\mathrm{CH}_{2}\right)_{n}-\mathrm{O}-\mathrm{CO}-$ $\left(\mathrm{CH}_{2}\right)_{14}-\mathrm{CH}_{3}$ (form a).

2. The specific formation of the ynolate $m / z 237$ ion from the melhoxy derivalive $[2-\mathrm{HI}]^{-}$deprolonated at the enolizable site suggests that the presence of the $m / z 237$ ion and its complementary ions (i.e., phenoxide, $m / z 123$ or 137 , ions) in CAD spectra of $[1-\mathrm{H}]^{-}$and $[3-\mathrm{H}]^{-}$are probably due to decomposition of the $\mathrm{HO}-\mathrm{C}_{6} \mathrm{H}_{4}-$ $\left(\mathrm{CH}_{2}\right)_{n}-\mathrm{O}-\mathrm{CO}-\mathrm{CH}^{-}-\left(\mathrm{CH}_{2}\right)_{13}-\mathrm{CH}_{3}$ form (form b).

\section{Orientation of Gas-Phase Deprotonation Induced by Amide Species}

Verification of this possible interpretation requires a comparison of behavior toward low-collision energy processes from both the isomeric deprotonated molecules (i.c., forms $\mathbf{a}$ and $\mathbf{b}, \mathrm{cq} \mathbf{1}, a$ and $b$ ). To achieve this goal, the deprotonation reaction is performed under labeled NICI-ND 3 conditions [11, 14]. Indeed, under these experimental conditions, phenol labeling occurs and yields labeled $\mathrm{DO}-$ molecules (noted as $\mathrm{M}_{\mathrm{d}}$ ). Then, competitive deprotonations at the phenol and enolizable sites lead to the phenuxide $\left[\mathbf{M}_{\mathbf{d}}\right.$ $-D]^{-}$and enolate $\left[M_{d}-H\right]^{-}$ions located at discrete mass-to-charge ratio values. Actually, in the NICI- $\mathrm{ND}_{3}$ mass spectrum of the phenol ester $\mathbf{1}_{\mathrm{d}}$, the major signal appears for $75 \%$ at $m / z 361$ (i.e., the phenoxide $\left[\mathrm{I}_{\mathrm{d}}-\right.$ D] ${ }^{-}$ion), and it is $25 \%$ shifted to $m / z 362$ (i.e., the enolate $\left[\mathbf{1}_{d}-\mathrm{H}\right]^{-}$ion), after correction of natural ${ }^{13} \mathrm{C}$ contribution of $m / z$ 361. Thus, deprotonation in NICI$\mathrm{ND}_{3}$ (or $\mathrm{NH}_{3}$ ) takes place $75 \%$ at the phenol site. A similar trend toward the $\mathrm{ND}_{3} / \mathrm{ND}_{2}^{-}$system characterizes the gas-phase reactivity of phenol ester 3 (eq 1, a and $b$ ):

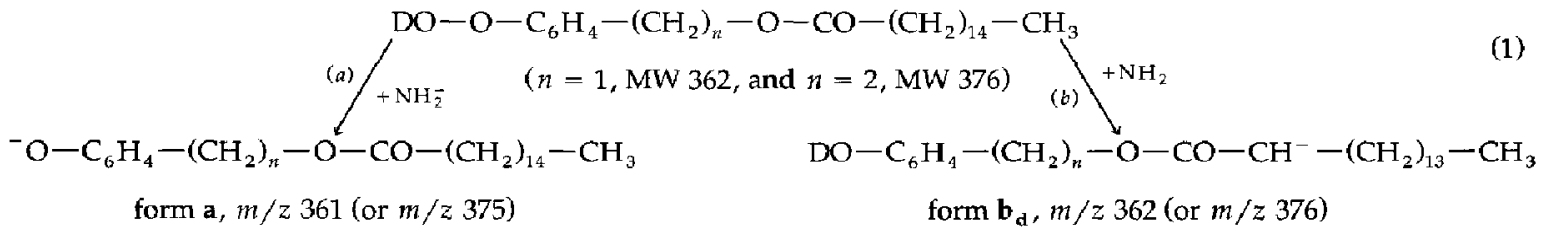

The acidity of ammonia [i.e., $\Delta G_{\text {acid }}^{o}\left(\mathrm{NH}_{3}\right)=1657 \mathrm{~kJ}$ $\mathrm{mol}^{-1}$ ] [15] is much lower than phenol and ester acidities [i.e., $\Delta G_{\text {acid }}^{\circ}\left(C_{6} \mathrm{H}_{5} \mathrm{OH}\right)=1432 \mathrm{~kJ} \mathrm{~mol}^{-1}$; for long chain esters, acidity is estimated to be approximately $\Delta \mathrm{G}_{\text {acid }}^{\circ}\left(\mathrm{CH}_{3}\left(\mathrm{CH}_{2}\right)_{n} \mathrm{COOCH}_{3}\right)=1478 \mathrm{~kJ} \mathrm{~mol}^{-1}$, with $n>10$; see ref 15 and footnote 1]. Proton abstrac-

\footnotetext{
${ }^{1}$ The acidity of long-chain compounds was estimated to be higher by $50 \mathrm{~kJ} \mathrm{~mol}^{-1}$ than that of the smaller molecule containing the same function (similar increment was used for estimating proton affinities of anions). This negative increment was appreciated from the acidity change measured from long-chain alcohols which is due to hydrocarbon chain coiling giving rise to a better negative charge solvation $\left[16,17\right.$ ]. Thus, from $\Delta G_{\text {acid }}^{\text {D }}\left(\mathrm{CH}_{3} \mathrm{COOCH}_{3}\right)=152 \mathrm{~g} \mathrm{~kJ} \mathrm{~mol} \mathrm{~mol}^{-1}$ [or $\mathrm{PA}\left({ }^{-} \mathrm{CH}_{2}-\mathrm{COOCH}, 3\right)=1556 \mathrm{~kJ} \mathrm{~mol}^{-1}$ ], $\Delta \mathrm{G}_{\mathrm{acid}}^{\circ}\left(\mathrm{CH}{ }_{3} \mathrm{COOH}\right)=1429$ $\mathrm{kJ}$ mol ${ }^{1}$ [or $\mathrm{PA}\left(\mathrm{CH}_{3} \mathrm{COO}\right)=1459 \mathrm{~kJ} \mathrm{~mol}{ }^{1}$ ], and $\Delta \mathrm{G}_{\text {acid }}^{\circ}\left(\mathrm{H}_{2} \mathrm{C}=\right.$ $\mathrm{C}=\mathrm{O})=1497 \mathrm{~kJ} \mathrm{~mol}^{-1}$ [or $\mathrm{PA}\left({ }^{-} \mathrm{IIC}=\mathrm{C}=\mathrm{O}\right)=1527 \mathrm{~kJ} \mathrm{~mol}^{-1}$ ] [15], the acidities (or proton affinities) of long-chain compounds can be estimated to have the following values: $\Delta \mathrm{G}_{\text {acid }}^{\circ}\left(\mathrm{CH}_{3}\left(\mathrm{CH}_{2}\right)_{n} \mathrm{COOR}\right)$ $=1478 \mathrm{~kJ} \mathrm{~mol}^{-1}\left[\right.$ or $\mathrm{PA}\left(\mathrm{CI}{ }_{3}\left(\mathrm{CH}_{2}\right)_{\pi-1} \mathrm{CH}^{-1}-\mathrm{COOR}\right)-1506 \mathrm{~kJ}$

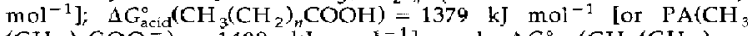
$\left.\left(\mathrm{CH}_{2}\right)_{r} \mathrm{COO}^{-}\right)=1409^{\mathrm{kJ} \mathrm{mol}} \mathrm{mol}^{-1}$ and $\Delta \mathrm{G}_{\mathrm{acid}}\left(\mathrm{CH}_{3}\left(\mathrm{CH}_{2}\right)_{m-1}\right.$ $\mathrm{HC}=\mathrm{C}=\mathrm{O})=1447 \mathrm{~kJ} \mathrm{~mol}^{-1}$ (or $\mathrm{PA}\left(\mathrm{CH}_{3}\left(\mathrm{CH}_{2}\right)_{n} \mathrm{C}^{-}=\mathrm{C}=\mathrm{O}\right)$ $=1477 \mathrm{~kJ} \mathrm{~mol}^{-1} \mathbf{l}$.
}

tion from phenol and ester sites is consistent with acidity values of reactants, assuming that this ion-molecule reaction, produced in a high-pressure source, is thermodynamically controlled [18]. This control explains the observed orientation that favors the phenol deprotonation relative to ester. Therefore, using NICI-ND ${ }_{3}$ conditions, it is possible to distinguish $\mathbf{a}$, $\left[\mathbf{M}_{\mathbf{d}}-\mathrm{D}\right]^{-}$, and $\mathbf{b}_{\mathbf{d}},\left[\mathbf{M}_{\mathbf{d}}-\mathrm{H}\right]^{-}$.

Investigation of both molecular species (i.e., the a and $\mathbf{b}_{\mathbf{d}}$ forms) by low-energy collisions (Table 2) shows that these isomeric $a$ and $b_{\mathrm{a}}$ forms lead to the different decomposition pathways. The nonoccurrence of the reversible $\mathbf{a} \rightleftarrows \mathbf{b}_{\mathrm{d}}$ isomerization is evidenced by the different fingerprints characterizing both CAD spectra. To produce such isomerization, a proton transfer should proceed from the enolizable site to the phenoxide site (and the reverse); however, because these are not sterically neighboring sites, proton migration is hindered. Furthermore, some information about the origin of the different pairs of complementary frag- 
Table 2. Shifting of signals ${ }^{a}$ observed in low-energy CAD spectra of $\left[\mathbf{M}_{d}-\mathrm{D}\right]^{-}$and $\left[\mathbf{M}_{d}-H\right]^{-}$ ions generated in NICI-ND ${ }_{3}$ from phenol esters $\mathbf{1}_{d}$ and $\mathbf{3}_{d}$

\begin{tabular}{|c|c|c|c|c|c|c|c|c|}
\hline \multirow[b]{2}{*}{ Phenol ester $\mathbf{1}_{\mathbf{d}}$} & \multicolumn{8}{|c|}{ Fragment ion intensities } \\
\hline & & 105 & 123 & 237 & 255 & 256 & 317 & 318 \\
\hline$\left[M_{d}-D\right]^{-}(m /<361)$ & & $\mathbf{3}$ & & & 100 & & 52 & \\
\hline \multirow{2}{*}[M_{d}-H]{$^{-}(m / z 362)$} & & $1^{b}$ & 48 & 20 & $69^{b}$ & $88^{b}$ & & $100^{b}$ \\
\hline & \multicolumn{8}{|c|}{ Fragment ion intensities } \\
\hline Phenol ester $\mathbf{3}_{\mathbf{d}}$ & $\overline{108}$ & 119 & 137 & 237 & 255 & 256 & 345 & 346 \\
\hline$\left[M_{d}-D\right]^{-}(m / z 375)$ & & 5 & & & 100 & & & \\
\hline$\left[M_{d}-H\right]^{-}(m / 2376)$ & 3 & $2^{b}$ & 65 & 31 & $74^{b}$ & $100^{\mathrm{t}}$ & - & 18 \\
\hline
\end{tabular}

${ }^{a}$ Intensities relative to the base peak.

${ }^{\mathrm{b}}$ Peaks related to natural ${ }^{13} \mathrm{C}$ contribution of the $\left[\mathrm{M}_{A}-\mathrm{D}\right]^{-}$ions.

ment ions is provided in Table 2:

1. From the phenoxide $\left[M_{d}-D\right]^{-}$ions, pairs of the complementary fragment ions at $m / z \quad 123-237$ for $1_{\mathrm{d}}$ ( or $m / z$ 137-237 for 3 ) are not produced. Mainly, specific formation of the carboxylate $m / z 255$ ion (for $\mathbf{1}_{\mathrm{d}}$ and $\mathbf{3}_{\mathrm{d}}$ ) and $m / z 317$ ion (for $\mathbf{1}_{\mathrm{d}}$ ) occurs; and

2. From the labeled enolate $\left[\mathbf{M}_{d}-\mathbf{H}\right]^{-}$ions, the reverse situation is observed because the complementary fragment ions at $m / z 123$ and 237 (for $1_{d}$ ) are produced and a similar pair (i.e., at $m / z 137$ and 237 ) is formed by decomposition of the selected $\left[3_{\mathrm{d}}-\mathrm{H}\right]^{-}$ion. Note that signals at $\mathrm{m} / z 256$ and 255 (and $m / z 105$ and 318 for $1_{d}$ and $m / z 119$ for $3_{d}$ ) are very likely to be generated from decomposition of phenoxide parent ions containing a natural ${ }^{13} \mathrm{C}$ contribution of $\left[\mathbf{M}_{\mathbf{d}}-\mathrm{D}\right]^{-}$ions (see above).
Note that the labeled enolate $\left[3_{d}-\mathrm{H}\right]^{-}$ion specifically forms the labeled $m / z 346$ and 108 ions (in weak abundances) instead of producing the $m / z 345$ and 107 fragment ions. This contrasts with the ions formed at $m / z 137$ and 237 that do not carry a deuterium atom.

\section{Competitive Stepwise Decomposition of the Enolate} $\left[M_{d}-H\right]^{-}$ions $\left(b_{d}\right.$ Form $)$ Prepared in NICI-ND

The presence of the nonshifted pair of peaks at $\mathrm{m} / \mathrm{z}$ 123-237 in the CAD spectrum of the labeled enolate $\left[\mathbf{1}_{\mathbf{d}}-\mathrm{H}\right]^{-}$ions and at $m / z \quad 137-237$ from $\left[3_{\mathbf{d}}-\mathrm{H}\right]^{-}$ indicates that labeling at the phenol site is specifically lost. This can be rationalized by considering that the enolate parent ions undergo decomposition via a step-

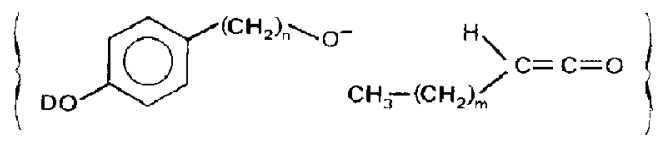<smiles></smiles>

$\underline{1}_{d}, n=1$ $\underline{3}_{d}, n=2$ Ion $\left[M_{d}-H\right]^{-}$, Form $h_{d}$<smiles></smiles>

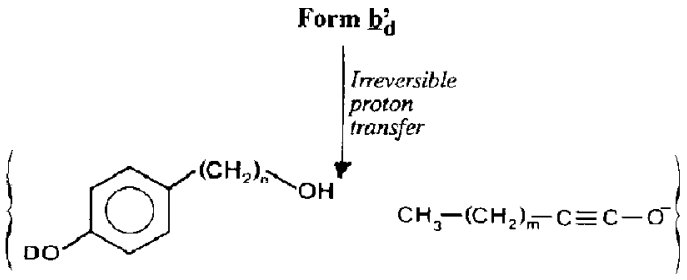

$\mathrm{m} / \mathbf{z} 237$<smiles>COc1ccc(C=CO)cc1</smiles>

$\underline{1}_{\mathrm{d}}, \mathrm{m} / \mathbf{z} 123$

$\underline{\mathbf{3}}_{\mathrm{d}}, \mathbf{m} / \mathbf{z} 137$

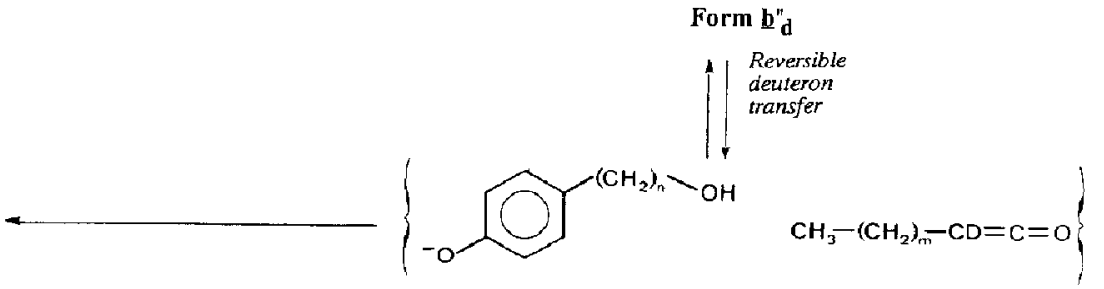

Form $b^{n "}$

Figure 1. Stepwise fragmentation of labeled $\mathbf{b}_{\mathbf{d}}$ ion via formation of the ion-dipole $\mathbf{b}_{d}^{\prime}, \mathbf{b}_{\mathbf{d}}^{\prime \prime}, \mathbf{b}_{\mathbf{d}}^{u t}$ intermediates. 
wise process through isomerization into an ion-dipole b' intermediate, as described previously for aliphatic esters (Figure 1) [4, 5, 10-13].

Ester bond cleavage induced by negative charge at the enolizable position yields an alkoxide-ketene complex (the $\mathbf{b}_{\mathbf{d}}^{\prime}$ form; Figure 1). This labeled intermediate competitively undergoes different reactions.

Direct specific loss of $\mathrm{CH}_{2} \mathrm{O}$ from $\left[3_{d}-\mathrm{H}^{-}(\mathrm{m} / \mathrm{z} 376)\right.$. This yields the $m / z 346$ ion (eq $2 a$ ), which dissociates into $m / z 108$ (with a very weak abundance) by ketene elimination without losing deuterium (eq $2 b$ ). This suggests that $m / z 108$ should be generated following $\mathrm{CH}_{2} \mathrm{O}$ elimination from $\left[3_{\mathrm{d}}-\mathrm{H}\right]^{-}$(or from the fragment $m / z 346$ ion) rather than from consecutive de- compositions via formation of the $m / z 137$ ion in which labeling is specifically lost. Such a mechanism has been proposed by Bowie and co-workers [19] to explain the loss of formaldehyde by a stepwise decomposition of the fragment $\mathrm{C}_{6} \mathrm{H}_{5}-\left(\mathrm{CH}_{2}\right)_{2}-\mathrm{O}^{-}$alkoxide. The ketene loss (eq $2 b$ ) probably competes with a more favorable formation of the ynolate $\mathrm{m} / \mathrm{z} 237$ ion (Table 2) through proton transfer from the ketene neutral to the benzylide moiety (eq $2 c$ ) if the reaction is exothermic. Analysis of CAD spectrum of the enolate $\left[3_{\mathrm{d} 2}-\mathrm{H}\right]^{-}$species $(m / z 377)$ confirms the proposed mechanisms concerning the fragment benzylide ions, which stay unshifted at $m / z 107$. This result also shows that if proton transfers occur, they specifically take place from the acidic sites.

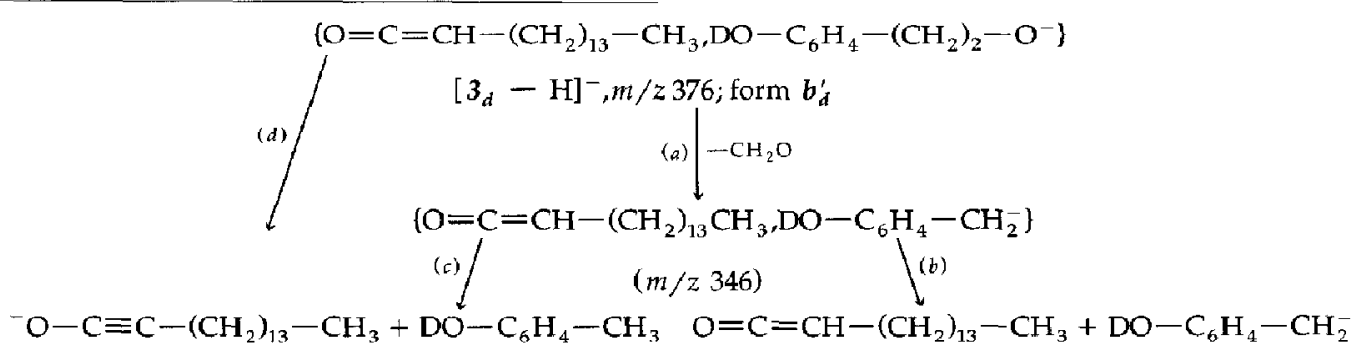

$m / z 237$

No information is provided in the literature about the relative proton affinities of the benzylide $\mathrm{HO}-$ $\mathrm{C}_{6} \mathrm{H}_{4}-\mathrm{CH}_{2}^{-}(\mathrm{m} / z 107)$ and the long-chain ynolate $\mathrm{CH}_{3}-\left(\mathrm{CH}_{2}\right)_{13}-\mathrm{C}=\mathrm{C}-\mathrm{O}^{-}(\mathrm{m} / z$ 237) ions; however, approximative calculations of the thermochemistry of proton transfer can be achieved from data reported in the literature (ref 15 and footnote 1). Indeed, proton affinity (PA) values of such benzylides can be estimated if one considers that substituted $\mathrm{X}-\mathrm{C}_{6} \mathrm{H}_{4}-\mathrm{CH}_{2}^{-}$benzylides $\left(\mathrm{X}=\mathrm{NO}_{2}, \mathrm{CF}_{3}, \mathrm{CN}\right.$, $\mathrm{CHO}, \mathrm{Cl}, \mathrm{CO}_{2} \mathrm{CH}_{3}$, and $\mathrm{CH}_{3}$ ) are characterized by $\mathrm{PA}$ values higher by at least $100 \mathrm{~kJ} \mathrm{~mol}^{-1}$ than those of the corresponding substituted $\mathrm{X}-\mathrm{C}_{6} \mathrm{H}_{4}-\mathrm{O}^{-}$phenoxides [15]. On the other hand, since PA(HO$\left.\mathrm{C}_{6} \mathrm{H}_{4}-\mathrm{O}^{-}\right)=1466 \mathrm{~kJ} \mathrm{~mol}^{-1}$, then PA(HO$\mathrm{C}_{6} \mathrm{H}_{4}-\mathrm{CH}_{2}^{-}$) should be close to $1566 \mathrm{~kJ} \mathrm{~mol}^{-1}$. This value is much higher than that of the long-chain ynolates [i.e., $\mathrm{PA}\left(\mathrm{CH}_{3}\left(\mathrm{CH}_{2}\right)_{n} \mathrm{C}=\mathrm{C}-\mathrm{O}^{-}\right)=1477 \mathrm{~kJ}$ $\mathrm{mol}^{-1}$, with $n>10$, estimated from $\mathrm{PA}\left(\mathrm{HC}=\mathrm{C}-\mathrm{O}^{-}\right)=1527 \mathrm{~kJ} \mathrm{~mol}^{-1}$; ref 15 and footnote 1]. Therefore, proton transfer from ketene to benzylide species is strongly exothermic (i.e., by approximately $89 \mathrm{~kJ} \mathrm{~mol}^{-1}$ ).

Further isomerization by exathermic proton transfer. This occurs from ketene to the $\mathrm{DO}-\mathrm{C}_{6} \mathrm{H}_{4}-\mathrm{CH}_{2}-\mathrm{O}^{-}$ alkoxide (from $1_{d}$ ) yielding the $b_{d}^{\prime \prime}$ form. Because it is exothermic by $69 \mathrm{~kJ} \mathrm{~mol}^{-1}$ [value estimated considering that $\mathrm{PA}\left(\mathrm{HO}-\mathrm{C}_{6} \mathrm{H}_{5}-\mathrm{CH}_{2} \mathrm{O}^{-}\right)$is similar to $\mathrm{PA}\left(\mathrm{C}_{6} \mathrm{H}_{5}-\mathrm{CH}_{2} \mathrm{O}^{-}\right)=1546 \mathrm{~kJ} \mathrm{~mol}^{-1}$, a value much higher than $\mathrm{PA}\left(\mathrm{CH}_{3}\left(\mathrm{CH}_{2}\right)_{n} \mathrm{C}=\mathrm{CO}^{-}\right), 1477 \mathrm{~kJ} \mathrm{~mol}^{-1}$; refs 15 and 20 and footnote 1 ], this proton transfer takes place. In the case of a similar proton transfer to $\mathrm{DO}-\mathrm{C}_{6} \mathrm{H}_{4}-\mathrm{CH}_{2}-\mathrm{CH}_{2}-\mathrm{O}^{-}$(for $3_{\mathrm{d}}$ ), the exothermicity does not differ because $\mathrm{PA}\left(\mathrm{HO}-\mathrm{C}_{6} \mathrm{H}_{4}-\right.$ $\left.\left(\mathrm{CH}_{2}\right)_{2}-\mathrm{O}^{-}\right)$can be estimated to be $1549 \mathrm{~kJ} \mathrm{mul}^{-1}$ (the estimated PA value is considered intermediate to

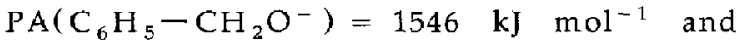
$\mathrm{PA}\left(\mathrm{C}_{6} \mathrm{H}_{5}\left(\mathrm{CH}_{2}\right)_{3} \mathrm{O}\right)=1552 \mathrm{~kJ} \mathrm{~mol}{ }^{1}$ ) [20].

Furthermore, the isomeric $\mathbf{b}_{\mathbf{d}}$ complex also undergoes competitive reactions either by direct dissociation into the ynolate $\mathrm{O}-\mathrm{C}=\mathrm{C}-\left(\mathrm{CH}_{2}\right)_{13}-\mathrm{CH}_{3}$ fragment ion $(m / z 237)$ or via proton (or deuteron) transfer from the phenol site to the ynolate moiety, yielding the $\mathbf{b}_{\mathbf{d}}^{\prime \prime \prime}$ form (Figure 1), which can dissociate into the phenoxide ${ }^{-} \mathrm{O}-\mathrm{C}_{6} \mathrm{H}_{4}-\left(\mathrm{CH}_{2}\right)_{n} \mathrm{OH}$ daughter ions (i.e., $m / z 123$ and 137 for $\mathbf{1}_{\mathbf{d}}$ and $\mathbf{3}_{\mathbf{d}}$, respectively). The latter proton migration is possible because the PA of the ynolate (i.e., $1477 \mathrm{~kJ} \mathrm{~mol}^{-1}$ ) (footnote 1) is slightly higher than that of the phenoxide $\mathrm{HO}-\left(\mathrm{CH}_{2}\right)_{n}-$ $\mathrm{C}_{6} \mathrm{H}_{4}-\mathrm{O}^{-}$ion [value assumed to be similar to $\left.\mathrm{PA}\left(\mathrm{H}_{3} \mathrm{C}-\mathrm{C}_{6} \mathrm{H}_{5}-\mathrm{O}^{-}\right)=1466 \mathrm{~kJ} \mathrm{~mol}^{-1}\right][15]$, making this proton transfer weakly exothermic (i.e., by $11 \mathrm{~kJ}$ $\mathrm{mol}^{-1}$ ). This explains the observed higher abundance of phenoxide $m / z 123$ and 137 ions (for $1_{d}$ and $3_{d}$ r respectively) relative to the ynolate $m / z 237$ ion. Although this latter proton migration ( $\mathbf{b}_{\mathbf{d}}^{\prime \prime}$ isomerization) is likely to be reversible, the former proton transfer from the benzylic or homobenzylic position, occurring 
in the first step (i.e., $\mathbf{b}_{\mathbf{d}}^{\prime}$ isomerization step), was not reversible (too exothermic). This is demonstrated by the absence of the shifted fragment ions at $m / z 123$ and 137. Indeed, if the $\mathbf{b}_{\mathbf{d}}^{\prime \prime} \rightarrow \mathbf{b}_{\mathbf{d}}^{\prime}$ process occurs, as well as $\mathbf{b}_{\mathbf{d}}^{\prime \prime} \rightarrow \mathbf{b}_{\mathbf{d}}^{\prime \prime}$, then labeled phenoxide $m / z 124$ and 138 should be observed, although this is not the case.

Confirmation of the origin (i.e., at the enolizable site of the ynolate form) of the first proton transferred during the $\mathbf{b}^{\prime} \rightarrow \mathbf{b}^{\prime \prime}$ isomerization is provided by anal$y$ sis of the CAD spectrum of the labeled enolate $\left[3_{\mathbf{d} 2}-\right.$ $\mathrm{D}]^{-}$parent ion $\left(m / z, 376\right.$, prepared in NICI-NH ${ }_{3}$ from palmintate $3_{\mathbf{d} 2}$; Table 3 ). Indeed, the signal at $m / z 237$ is not shifted at $m / z 238$, which means that deuterium at the enolizable site is specifically eliminated. Alternatively, the produced phenoxide $m / z 138$ fragment ion specifically preserves the deuterium atom, transferred from the ketene moiety to alkoxide via $\mathbf{b}_{\mathfrak{d}}^{\prime} \rightarrow \mathbf{b}_{\mathbf{d}}^{\prime \prime}$ isomerization. This therefore confirms that the first proton transfer is not a reversible process, as assumed above. Note that CAD spectrum of $m / z 376$ displays a fragment ion at $m / z$ 256, which cannot be attributed to decomposition of the enolate $\left[3_{\mathrm{d} 2}-\mathrm{D}^{-}\right.$ion $(m / z 376)$. The $m / z 256$ ion is very likely produced by fragmentation of the isotopomeric $m / z \quad 376$ ion, $\left[3_{d}-\mathbf{H}\right]$ (mainly composed of the phenoxide form), which is due to the presence of monolabeled ester (approximately a $10 \%$ contribution). This specificity is consistent with the assumption (below) as to the origin of ions at $m / z 255$ and 256 observed in the CAD spectrum of the selected enolate $\left[3_{\mathbf{d}}-\mathbf{H}\right]^{-}$ion (Table 2) (as well as $m / z$ 255, 256, and 318 from $\left[1_{d}-H\right]^{-}$), which were attributed to the natural ${ }^{13} \mathrm{C}$ contribution of the phenoxide $\left[\mathbf{3}_{\mathbf{d}}-\mathrm{D}\right]^{-}$.

Finally, this model also allows rationalization of the decomposition of the deprotonated methoxy $[2-\mathrm{H}]^{-}$ ion, $m / z 375$ (produced exclusively within the $b$ form in NICI- $\mathrm{NH}_{3}$ ), which specifically undergoes the pair of fragment ions (Table 1) at $m / z 137$ (i.e., $\mathrm{H}_{3} \mathrm{CO}-\mathrm{C}_{6} \mathrm{H}_{4}-\mathrm{CH}_{2}-\mathrm{O}^{-}$) and $m / z \quad 237$ [i.e., $\left.\mathrm{CH}_{3}\left(\mathrm{CH}_{2}\right)_{13}-\mathrm{C} \equiv \mathrm{C}-\mathrm{O}^{-}\right]$without carboxylate ion formation. Furthermore, the abundance of the ynolate $m / z 237$ fragment ion is higher than that of the alkox- ide $m / z 137$ ion, which contrasts with the decomposition of deprotonated phenol esters ( 1 and 3 ). This reversed behavior is expected because the acidity of ketene is higher than that of para-methoxybenzyl alcohol and therefore proton transfer is endothermic, which confirms our assumption that the $\mathbf{b}^{\prime} \rightarrow \mathbf{b}^{\prime \prime}$ step is an irreversible pathway.

\section{Stepwise Decomposition of the Phenoxide $\left[\boldsymbol{M}_{d}-\right.$ $D^{-}$Ions (a Form) Prepared in NICI-ND 3}

From the unlabeled phenoxide a form, the ester bond cleavage can be promoted by the negative charge via a long-distance process without undergoing total dissociation. Indeed, the fragmentation of $\left[\mathrm{M}_{\mathbf{d}}-\mathrm{D}\right]^{-}$can be interpreted, assuming that phenoxide parent ions lead to ion-dipole intermediates (i.e. the $a^{\prime}$ form), as shown in Figure 2. The large difference observed for ratios of the abundances of complementary fragment ions (i.e., $[m / z 255] \gg[m / z$ 105] for 1 and $[m / z$ $255] \gg[m / z 119]$ for 3 ) shows that this complex must dissociate into the carboxylate $m / z 255$ fragment ion rather than preferentially undergoing proton transfer (i.e., $\mathbf{a}^{\prime} \rightarrow \mathbf{a}^{\prime \prime}$ isomerization; Figure 2); however, this dissociation competes with loss of $\mathrm{CO}_{2}$ from the $\mathrm{a}^{\prime}$ form, as shown by decomposition of the phenoxide $\left[\mathbf{1}_{\mathrm{d}}-\mathrm{D}\right]^{-}$ion (eq 3; Table 2). From the $\mathbf{a}^{\prime}$ form, remote charge processes could yield a $\mathrm{CO}_{2}$ elimination; however, the additional $\mathrm{CH}_{2}-\mathrm{CH}_{2}$ bond cleavages, which characterize remote charge decomposition of carboxylate ions, are observed in very weak yields (not reported here). Moreover, the particular loss of $\mathrm{CO}_{2}$ is not enhanced by increasing the collision energy.

Recently, the production of fragment ions has been reported [21] due to loss of low-mass neutral molecules (e.g., loss of $\mathrm{CO}$ and $\mathrm{C}_{2} \mathrm{O}_{2}$ ) from ion-dipole complexes generated from (acyloxy)acetates under collision conditions (in the kiloelectron volt energy range). The fragment ion produced was characterized by its ion-dipole structure, as with the parent ions, without involving an ion-dipole rearrangement into more stable ion species (e.g., formation of covalent bonds):

$$
\begin{aligned}
& \text { ) } \\
& \left({ }^{-} \mathrm{O}-\mathrm{CO}-\left(\mathrm{CH}_{2}\right)_{14}-\mathrm{CH}_{3}, \mathrm{O}=\mathrm{C}_{6} \mathrm{H}_{4}=\mathrm{CH}_{2}\right\} \\
& \text { (form } a^{\prime}, m / z 361 \text { ) } \\
& m / z 255 \\
& \left.\mathrm{I}^{-}\left(\mathrm{CH}_{2}\right)_{14}-\mathrm{CH}_{3}, \mathrm{O}=\mathrm{C}_{6} \mathrm{H}_{4}=\mathrm{CH}_{2}\right\}+\mathrm{CO}_{2} \\
& \mathrm{O}=\mathrm{C}_{6} \mathrm{H}_{4}=\mathrm{CH}^{-}+\mathrm{OC}=\mathrm{CH}-\left(\mathrm{CH}_{2}\right)_{13}-\mathrm{CH}_{3} \text {. } \\
& m / z 105
\end{aligned}
$$$$
\mathrm{O}=\mathrm{C}_{6} \mathrm{H}_{4}=\mathrm{CH}_{2}+{ }^{-} \mathrm{O}-\mathrm{CO}-\left(\mathrm{CH}_{2}\right)_{14}-\mathrm{CH}_{3}
$$

In our case, the $m / z 317$ ion produced with an ion-dipole structure should form the $\mathrm{O}=\mathrm{C}_{6} \mathrm{H}_{4}=\mathrm{CH}^{-}$ benzylide $(m / z 105$, for 1) via proton transfer rather than $\mathrm{CH}_{3}-\left(\mathrm{CH}_{2}\right)_{13}-\mathrm{CH}_{2}^{-}$. Actually, the latter frag- ment ion is not detected, and the $m / z 105$ en-ylide is produced in a weak yield (relative to $m / z 255$ ), and it appears to be particularly stable for the fragment $\mathrm{m} / \mathrm{z}$ 
Table 3. Shifting of signals ${ }^{n}$ observed in low-energy CAD spectra of $\left[3_{d 2}-D\right]^{-}$and $\left[3_{d 2}-H\right]^{-}$ ions generated in NICI- $\mathrm{NH}_{3}$ from labeled phenol stearate $3_{\mathrm{d} 2}$

\begin{tabular}{|c|c|c|c|c|c|c|c|c|}
\hline & \multicolumn{8}{|c|}{ Fragment ion intensities } \\
\hline & 107 & 119 & 138 & 237 & 238 & 256 & 257 & 347 \\
\hline$\left[3_{d 2}-D\right]^{-}(m / x 376)$ & 3 & $1^{b}$ & 100 & 42 & - & $65^{b}$ & - & 34 \\
\hline$\left[3 \mathrm{dz}_{2}-\mathrm{H}\right]^{-}(\mathrm{m} / 2377)$ & $<1^{\circ}$ & 4 & $2.5^{\mathrm{c}}$ & $<1^{c}$ & $1.5^{\mathrm{c}}$ & - & 100 & - \\
\hline
\end{tabular}

317 ion. This suggests that the intermediate $\mathrm{m} / \mathrm{z} 317$ ion is rearranged into a stable covalent form that hinders the production of the benzylide $m / z 105$ ion (eq 4). Therefore, the $\mathrm{CO}_{2}$ elimination from the carboxylate moiety of the a' form would be accompanied (probably by assistance) by a $\mathrm{C}-\mathrm{C}$ bond formation by electrophilic attack of trienone on the unstable ylide site, yielding a more stable ion, possibly with a phenoxide structure (eq 4$)$ :

$$
\begin{gathered}
\left\{\mathrm{O}=\mathrm{C}_{6} \mathrm{H}_{4}=\mathrm{CH}_{2},{ }^{-} \mathrm{O}_{2} \mathrm{C}-\left(\mathrm{CH}_{2}\right)_{14}-\mathrm{CH}_{3}\right\} \longrightarrow \\
-\mathrm{O}-\mathrm{C}_{6} \mathrm{H}_{4}-\mathrm{CH}_{2}-\left(\mathrm{CH}_{2}\right)_{14}-\mathrm{CH}_{3}+\mathrm{CO}_{2} \\
m / z 317
\end{gathered}
$$

This presumed mechanism, which involves alkyl group migration (i.e., $\mathrm{C}-\mathrm{C}$ bond formation) in the ion-dipole a' complex during $\mathrm{CO}_{2}$ loss, can be compared to that which described the loss of $\mathrm{CO}$ from deprotonated 2,3-butanedione [22] and protonated 2,2-dimethyl-3,5hexanedione [23]. This $\mathrm{CO}_{2}$ loss is influenced by the structure of the unsaturated neutral moiely of the complex, because from 3 (Table 2), where the ester is at homobenzylic position, the $\left[3-\mathrm{H}-\mathrm{CO}_{2}\right]^{-}$ion is not formed. This observed structural effect can be due to a different electrophilic affinity of the unsaturated neutral toward the en-ylide species in the $\mathbf{a}^{\prime}$ form.

Alternatively, within the a' structure, the parent ion could undergo isomerization to the $a^{\prime \prime}$ form by an unfavored proton transfer from the trienic neutral (as methylen-2,5-cyclohexadien-4-one for 1 and 4,7spiro[2,5]octadien-6-one or ethynyl-2,5-cyclohexadien4-one isomer for 3 ) to carboxylate (Figure 2), providing a serond pathway to the en-ylide $m / z 105$ inn for 1 (or $m / z 119$ for 3); however, this process appears to be strongly hindered (less $6 \%$ of the carboxylate ions). This trend suggests that such a proton transfer process yielding the isomeric a" form must be too endothermic.

Without information from the literature about acidities of pertinent unsaturated neutrals, it is difficult to rationalize why deprotonation of these dienones or trienones cannot occur; however, the acidities of these dienone and trienone neutrals should be assumed to be weaker than that of phenol $\left[\Delta G_{\text {acid }}^{\circ}\left(\mathrm{C}_{6} \mathrm{H}_{5} \mathrm{OH}\right)=\right.$ $1432 \mathrm{~kJ} \mathrm{~mol}^{-1}$ ] [15]. Comparison of these acidity val-

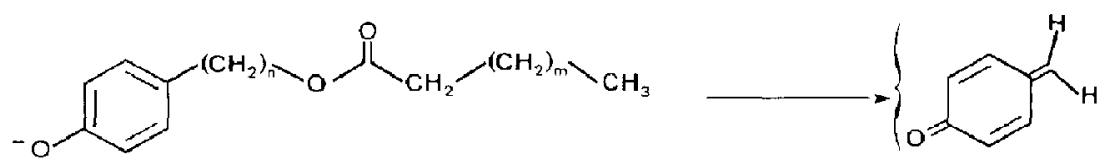

$$
\underline{\underline{1}}_{d}, n=1, \text { lon }\left[M_{d}-D\right]^{-}, \text {Form a }
$$$$
\mathrm{CH}_{3}-\left(\mathrm{CH}_{2}\right)_{\mathrm{m}}-\mathrm{CH}_{2}-\mathrm{COO}^{-}
$$
$\mathrm{m} / \mathrm{z} 255$<smiles>O=CC1C=CC(=O)C=C1</smiles><smiles></smiles>

$\mathrm{m} / \mathrm{x}, 105$<smiles>CCCCCCCCCCCCC(=O)OC</smiles>

Form $\mathbf{a}^{\prime}$

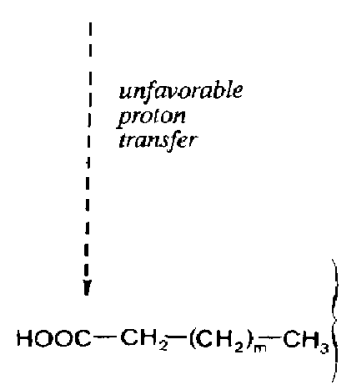

Form $\underline{a}^{n}$

Figure 2. Stepwise fragmentation of phenoxide ion (form a) via formation of ion-dipole intermediates (forms a' and a") produced from 1. 
ues to those of fatty acids $\left[\Delta \mathrm{G}_{\mathrm{acid}}^{\circ}\left(\mathrm{CH}_{3}\left(\mathrm{CH}_{2}\right)_{n} \mathrm{COOH}\right)\right.$ $=1379 \mathrm{~kJ} \mathrm{~mol}^{-1}$, for $n>10$, estimated from $\Delta G_{\text {acid }}^{\circ}\left(\mathrm{CH}_{3}-\mathrm{COOH}\right)=1429 \mathrm{~kJ} \mathrm{~mol}^{-1}$ lower by $53 \mathrm{~kJ}$ $\mathrm{mol}^{-1}$; footnote 1] suggests that proton transfer from the unsaturated neutral to carboxylate is strongly unfavorable, because it is too endothermic ( $>53 \mathrm{~kJ} \mathrm{~mol}^{-1}$ ). Consequently, the formation of the ion-dipole $a^{\prime \prime}$ intermediate, able to form the enylide fragment ions at $m / z 105$ (or $m / z 119$ ), is not the preferential pathway. This explains its weak abundance relative to the abundance of the complementary $m / z 255$ ion. This unambiguous behavior demonstrates that ion-dipole complex evolution through different decomposition pathways depends on the relative acidities of both moieties that constitute the ion-dipole complex. Too great a difference in acidity certainly provides direct dissociation of the $\mathbf{a}^{\prime}$ intermediate within a rate constant very much higher than that of the eventual proton transfer, yielding the $a^{\prime} \rightarrow a^{\prime \prime}$ isomerization.

\section{Conclusion}

This study primarily demonstrates that under NICI$\mathrm{NH}_{3}$, deprotonation of phenol fatty acid esters (a medium-sized molecule) occurs mainly at the most acidic site (i.e., at the phenol group, for $75 \%$ ). By using gas-phase labeling conditions (with $\mathrm{ND}_{3}$ ), both produced phenoxide $\left[\mathbf{M}_{d}-\mathrm{D}\right]^{-}$and enolate $\left[\mathbf{M}_{\mathbf{d}}-\mathrm{H}\right]^{-}$ ions with different abundances, according to the relative acidities (as a thermothermically controlled process) of both sites, that are higher than that of the ammonia reagent. These isomeric species can be distinguished by analysis of low-collision energy processes. Indeed, ion decomposition depends on the charge location, showing that both isomeric parent structures are not convertible. On the other hand, the CAD spectra reveal several properties that are characteristic of the structure of the selected deprotonated molecules, such as the enolate or phenoxide structures.

In particular, it is demonstrated by labeling that the isomeric enolate parent ions (containing labeling at the phenol site) isomerize prior to dissociation into an ion-dipole complex according to a particular ester cleavage mode. The complex produced competitively undergoes: (1) ion isomerization via a like irreversible proton transfer, and (2) direct ion decomposition by loss of $\mathrm{CH}_{2} \mathrm{O}$ from the deprotonated homobenzylic ester.

Actually, oricntation of the different reaction pathways (i.e., dissociation into pairs of fragment ions or isomerization via proton migration) of each intermediate is influenced by the exothermic character of the involved proton transfer, which competes with direct fragmentations of complexes. In particular, relative abundances of the fragment ions of the labeled phenol esters (and methoxy derivative) demonstrate that the first proton transfer is not reversible, in contrast to the second proton migration. This appears to be consistent with the estimated proton affinities of anion and acid- ity values of neutrals present in the ion-dipole intermediate. The occurrence of these different exothermic proton transfers indicates that the energy barrier for these isomerization pathways must be low [24] and, in particular, when isomerization is reversible.

A different trend characterizes the phenoxide parent ion, which fragments via a different ester cleavage mode, and leads directly to carboxylate species rather than undergoing isomerization by proton transfer prior to decomposition. The unexpected $\mathrm{CO}_{2}$ expulsion from the deprotonated benzylic ester seems to occur by direct decomposition of the ion-dipole intermediate, which is likely to be decomposed by an internal electrophilic attack strongly influenced by the substrate structure.

\section{Experimental}

\section{Synthesis}

$-4^{\prime}$-Methoxy-benzyl palmitate ester 2. This palmitate ester was prepared according to the method proposed by Mellon-Nussbaum et al. [25]. One gram of 4'methoxybenzyl alcohol (Fluka) was dissolved in $20 \mathrm{~mL}$ of anhydrous pyridine $\left(0^{\circ} \mathrm{C}\right)$ under nitrogen, and 4.5 $\mathrm{mL}$ of palmitoyl chloride (Fluka) was added. The mixture was stirred at room temperature for $15 \mathrm{~h}$. It was then acidified $(10 \% \mathrm{HCl})$, and the solution was extracted three times with ether $(20 \mathrm{~mL})$. The organic phase was washed with $10 \%$ aqueous sodium hydrogenocarbonate and then with water until neutral. Crude 4'-methoxy-benzyl palmitate ester (yield 69\%) was purified over a silica gel column [pentane ether 1:1 $(\mathrm{v} / \mathrm{v})]$ and eluted with benzene.

$-4^{\prime}-$ Hydroxy-benzyl palmitate ester 1 and $4^{\prime}$-hydroxy-2phenylethyl palmitate ester 3 . Similar conditions were used starting from (1) 4'-hydroxy-benzyl alcohol and (2) 4'-hydroxy-2-phenylethanol; however, dipalmitate was the major reaction product. It was hydrolyzed with $\mathrm{NaHCO}_{3}$; the labile phenolic ester was removed as follows: the ethereal solution was evaporated to dryness, and the resulting oil was dissolved in benzene $(5 \mathrm{~mL})$ to which $100 \mathrm{~mL}$ of methanol and $500 \mathrm{mg}$ of $\mathrm{NaHCO}_{3}$ were added. The mixture was heated overnight $\left(50-55^{\circ} \mathrm{C}\right)$, diluted with ether and chromatographed on a silica gel column. The column was developed with isooctane / benzene, first 1:1 $(\mathrm{v} / \mathrm{v})$, then $1: 3(\mathrm{v} / \mathrm{v})$. The palmitate ester was then eluted with benzene (yields; $45-51 \%$ ).

\section{$-\left[2^{\prime}, 2^{\prime} D_{2}\right] 4^{\prime}-$ hydroxy-benzyl palmitate ester $\mathbf{1}_{d 2}$}

1. Preparation of $2,2-D_{2}$ palmitic acid: Methyl palmitate $(600 \mathrm{mg})$ was refluxed for $18 \mathrm{~h}$ in dry deuterated methyl alcohol $(20 \mathrm{~mL})$ previously made alkaline with sodium metal ( $60 \mathrm{mg}$ ), in a slow current of nitrogen gas, with a calcium chloride guard tube, as described by Vetter et al. [26]. The reaction mixture 
was cooled to room temperature, and deuterium oxide $(3 \mathrm{~mL})$ was added. Further refluxing under the same conditions yields $2,2-\mathrm{D}_{2}$ palmitic acid (530 $\mathrm{mg}$ ).

2. Preparation of $2,2-\mathrm{D}_{2}$ palmitic acid chloride: $2,2-\mathrm{D}_{2}$ palmitic acid was then dissolved in benzene ( 2.5 $\mathrm{mL}$, sodium dried), and phosphorous pentachloride $(420 \mathrm{mg})$ was added. The solution was heated at $60-80{ }^{\circ} \mathrm{C}$ for $2 \mathrm{~h}$ under nitrogen atmosphere. $\alpha-\mathrm{D}_{2}$ palmitic acid chloride was then obtained after solvent removal under reduced pressure. The product was used immediately without further purification.

3. The condensation of 2,2- $\mathrm{D}_{2}$ palmitic acid chloride with hydroxybenzyl alcohol was carried out according to the previously described method to give $\left[2^{\prime}, 2^{\prime} \mathrm{D}_{2}\right]-4^{\prime}$-hydroxy-benzyl palmitate ester (yield $50 \%$ ). The labeling distribution at the enolizable position was $\mathrm{D}_{2}(90 \%)$ and $\mathrm{D}_{1}(10 \%)$ (measured by mass spectrometry in PICI- $\mathrm{NH}_{3}$ ).

\section{Mass Spectrometry}

Mass spectrometry and tandem mass spectrometry were performed on a triple quadrupole mass spectrometer (R30 10 Nermag, France). The NICI mass spectra were obtained using a direct introduction probe (DCI), where $1 \mu \mathrm{L}$ of sample solution $\left(1 \mu \mathrm{g} \mu \mathrm{L}^{-1}\right.$ in methanol) was placed on a heated tungsten filament that was maintained at $150{ }^{\circ} \mathrm{C}$. The following source operating conditions were used: emission current, 100 InA; repeller voltage, $0 \mathrm{~V}$; source temperature, $180^{\circ} \mathrm{C}$, and reagent gas pressure, $2 \times 10^{-4}$ torr (source housing pressure) in $\mathrm{NICI}-\mathrm{NH}_{3}$ (or $\mathrm{ND}_{3}$, obtained from CEA, France).

In the tandem mass spectrometry experiments, CAD spectra of deprotonated molecules were obtained by using argon as the collision gas at $3 \times 10^{-2}$ torr (measured just inside the collision cell housing) to yield single-collision conditions. The scan rate was $0.4 \mathrm{~s}$ for each CAD spectrum recorded using a PDP $11 / 73$ (with a Sidar data system). Each reported CAD spectrum is an average of at least 50 consecutive scans that were selected for optimum signal-to-noise ratio.

\section{References}

1. (a) McAdoo, D. J. Mass Spectrom. Rev. 1988, 7, 367; (b) Longevialle, P.; Botter, R. J. Chem. Soc., Chem. Commun. 1980, 823; (c) Bowen, R. D.; Williams, D. H. J. Chem. Soc., Chem.
Commun. 1980, 823; (d) Morton, T. H. Tetrahedron 1982, 38, 3195.

2. (a) Buwie, J. H. In Mass Specirumetry; Ruse, M. E., Ed. (Spetialist Periodical Reports). The Royal Society of Chemistry; London, 1989; Vol. 10, p. 145; (b) Bowie, J. H. Mass Spectrom. Rev. 1990, 9, 349.

3. Hayes, R. N.; Sheldon, J. C.; Bowie, J. H.; Lewis, D. E. J. Chem. Soc., Chem. Commun. 1984, 1431.

4. Budzikiewicz, H. Mass Spectrom. Reo. 1990, 9, 349.

5. Donnelli, A.; Chowdhury, S. K.; Harrison, A. G. Org. Mass Spectrom. 1989, 24, 89.

6. Promé, J. C.; Aurelle, H.; Promé, D.; Savignac, A. Org. Mass. Spectrom. 1987, 26, 6.

7. Cole, R. B.; Tabet, J. C.; Salles, C.; Jallageas, J. C.; Crouzet, J. Rapid Commun. Mass Spectrom. 1989, 3, 59.

8. Eckesley, M.; Bowie, J. H.; Hayes, R. N. Int. I. Mass Spectrom. Ion Processes 1989, 93, 199.

9. Waugh, R. J.; Bowie, J. H.; Hayes, R. N. Org. Mass Spectrom. $1991,26,250$.

10. Fournier, F.; Salles, $C_{\text {; }}$ 'labet, J. C.; Debrauwer, L.; Rao, L.; Paris, A.; Bories, G. Anal. Chim. Acta 1990, 241, 265.

11. Fournier, F.; Tabet, J. C.; Debrauwer, L.; Rao, D.; Paris, A.; Bories, G. Rapid Commun. Mass Spectrom. 1991, 6, 44.

12. (a) Hayes, R. N.; Bowie, J. H. J. Chem. Soc., Perkin Trans II 1986, 1827; (b) Stringer, M. B.; Bowie, J. H.; Eichinger, P. C. H.; Currie, G. J. J. Chem. Soc., Perkin Trans II 1987, 385.

13. Harrison, A. G.; Young, R. B. Int. J. Mass Spectrom. Ion Processes 1989, 94, 321.

14. (a) Beloeil, J. C.; Bertranne, M.; Stahl, D.; Tabet, J. C. I. Am. Chem. Soc. 1983, 105, 1355; (b) Hunt, D. F.; Sethi, S. K.; Shabanowitz, J. Environ. Health Perspect. 1980, 36, 33.

15. Lias, S. G.; Bartmess, I. E.; Liebman, J. L.; Holnes, J. L.; Levin, R. D.; Mallard, W. C. J. Phys. Chem. Ref. Data 1988, 17. Suppl. 1.

16. Boand, G.; Houriet, R.; Gäumann, T. I. Am. Chem. Soc. 1983, $105,2203$.

17. (a) Harrison, A. G. In Fundamentals of Gas Phase Ion Chemistry; Jenning, $\mathrm{K}$, Ed; NATO ASI Series, Series C, Vol. 347, p. 289, 1991; (b) Majumdar, K. T.; Clairet, F.; Tabet, J. C.; Cooks, R. G. I. Am. Chem. Soc. 1992, 114, 2897.

18. Sürig, T.; Grützmacher, H. F. Org. Mass Spectrom. 1989, 24, 851.

19. Raftery, H. J:; Bowie, I. H.; Sheldon, J. C. J. Chem. Soc., Perkin Trans II 1988, 363.

20. Graul, S. T.; Schnute, M. E.; Squires, R. R. Int. Mass Spectrom. Ion Processes 1990, 96, 1981.

21. Eichinger, P. C. H.; Hayes, R. N. N.; Bowie, J. H. J. Am. Chem. Soc. 1991, 113, 1949.

22. Chowdhury, S. K.; Harrison, A. G. Org. Mass Spectrom. 1989, 24,123 .

23. Grutzmacher, H. F,; Mazur, A. Org. Mass Spectrom. 1988, 23, 223.

24. Chowdhury, S. K: Harrison, A. G. Int. J. Mass Spectrom. Ion processes 1989, 92, 135.

25. Melton-Nussbaum, S. H.; Ponticarvo, L.; Schatz, F; Hochberg R. B. J. Biol. Chem. 1982, 10, 5678.

26. Vetter, W.; Meister, $W_{. j}$ Oesterholf, G. Org. Mass Spectrom. 1988, 23, 566 . 